\title{
Assesment of Risk Factors For Conversion To Open Surgery In Patients Undergoing Laparoscopic Cholecystectomy
}

\author{
Chaudhary Sanchit, Sharma Maneesh, Wig JD, Gupta NM, Mahajan Amit
}

\begin{abstract}
Background:Laproscopic cholecystectomy has become the gold standard for the surgical treatment of gall bladder disease, but conversion to open cholecystectomy is still inevitable in certain cases. Knowledge of the rate and impact of the underlying reasons for conversion could help surgeons during preoperative assessment and improve the informed consent of patients. This study was undertaken to review the rate and causes of conversion from laprascopic to open cholecystectomy.

Objectives: The aim of the study was to assess the risk factors for conversion of laparoscopic cholecystectomy to open cholecystectomy. Material And Methods: A Prospective non randomized study was conducted in the Department of General Surgery, Fortis Hospital Mohali, Punjab. Data collected will be fed in Microsoft excel work sheet and statistical analysis will be performed with SPSS software (SPSS, Chicago, Illinois, USA) using Chi Square Test. A univariate and multivariate analysis comparing the variables with conversion will be done. $p$ value $<0.05$ will be taken as significant.

Results: Out of 100 patients with gallbladder disease, 15 patients (15\%) were converted to open cholecystectomy. Elderly males $>60$ years were at significant risk for conversion to open procedure $(p=0.004)$ .5 patients presented with symptoms of acute cholecystitis were converted to open procedure $(p=0.00004)$. Ultrasonography finding of acute cholecystitis was highly significant ( $p<0.00004)$. ). Adhesions and fibrosis of Calot'striangle all were converted to open surgery $(p<0.001) .5$ out of 6 patients who underwent LC following ERCP required conversion to OC ( $p<0.001)$.

Conclusion: In conclusion significant risk factors for conversion were male gender, acute cholecystitis, dense adhesions, post ERCP and pre-operative USG findings.

Keywords: Laproscopic cholecystectomy, conversion rate, male gender, acute cholecystitis, dense adhesions
\end{abstract}

\section{Introduction}

Laparoscopic cholecystectomy ( L C ) has become the standard treatment for symptomatic gallstones replacing open cholecystectomy ( OC )1,2,3,4. More than $90 \%$ of cholecystectomies are performed laparoscopically for its well documented advantages4. Cholecystectomy cannot be completed laparoscopically in all patients and conversion to $\mathrm{OC}$ is then required5. A conversion to open surgery is reported to be necessary in $2 \%$ to $22 \%$ of cases in the literature of all attempted cholecystectomies 1,2 , Nearly two decades into the laparoscopic era in USA nationwide laparoscopic cholecystectomy conversion rates remain around 5\% to 10\%.3.Factors prompting conversion from LC to OC are not completely understood4,5. Various conversion reasons have been Identified- dense and extensive adhesions precluding clear vision in Calot's triangle Is the most common reason for conversion ( reported in upto 40\%), acute cholecystitis the reported conversion rate of $14 \%$ to $50 \%$, and small fibrotic contracted gallbladder making grasping and dissection of the gallbladder difficult $(12 \%)$. Other reported reasons for conversion are empyema of the gallbladder and gangrenous cholecystitis. Operative complications ( $8 \%$ to $15 \%$ )- uncontrolled bleeding or injury of the extrahepatic bile ducts also necessitate conversion to an open procedure 1 . The conversion to an open procedure should not be regarded as a failure or complication but as a conscious attempt to avoid life threatening complications. It is thus important to recognize patients with a higher risk of conversion in order to optimize planning the surgical procedure. Identification of risk factors for possible conversion to OC would be useful for both surgeons and patients. The present study is aimed at determining the conversion rate of LC and to identify the risk factors associated with conversion of LC to OC.

AIMS AND OBJECTIVES

To assess the risk factors for conversion of laparoscopic cholecystectomy to open cholecystectomy.

Study Design

\section{Material And Methods}

A Prospective non randomized study was conduced in the department of surgery in department of General Surgery,FortisHospital,Mohali Punjab, India. One hundred patients who underwent LC between February 2009 to December 2010 were studied. Data was Categorized accordingly to age, gender, 
comorbidities, preoperative investigations, operative findings, and factors for conversion to an open procedure. The inclusion criteria of cases In the study included symptomatic gallstone disease.

\section{Exclusion Criteria}

Suspicion of gallbladder cancer based on ultrasonography and computed tomography. A conversion to open procedure was needed when even after appropriate attempts, the procedure could not be accomplished laparoscopically without breaching the principles of the safety of laparoscopic procedure.

\section{Methods}

The preoperative work up included routine blood tests, liver and renal function tests, chest x ray, electrocardiography and ultrasonography of the abdomen. The patients were asked to sign a consent form for the surgery after discussing the benefits and risks of the procedure. The patients were admitted to the surgical ward for immediate postoperative care. All patients had oral liquids in the evening. They were discharged on next day after the operation.

\section{Operative Procedure}

The procedure was carried out using the standard four-port technique.The first port is a $10 \mathrm{~mm}$ infraumblical camera port inserted using the open technique method of $\mathrm{CO} 2$ insufflation. The other three ports $10 \mathrm{~mm}$ dissecting port in epigastrium, and two $5 \mathrm{~mm}$ ports in midclavicular line, and anterior axillary line are inserted under direct camera vision. The gallbladder was retracted from the fundus above the right lobe of the liver by the assistant. The anterior edge of the Hartman's pouch was retracted by the surgeon's left hand in an outward and lateral direction through the $5 \mathrm{mmm}$ port thus opening space for establishing the triangle of safety. The cystic artery was identified by gentle sweeping of the peritoneal covering. Lateral peritoneal attachment is then released. The cystic artery was then clipped and divided over the gallbladder wall. Cystic duct was then clipped and divided near its junction with the gallbladder infundibulum.

\section{Stastical analysis}

Data collected will be fed in Microsoft excel work sheet and statistical analysis will be performed with SPSS software ( SPSS, Chicago, Illinois, USA ) using Chi Square Test. A univariate and multivariate analysis comparing the variables with conversion will be done. $\mathrm{p}$ value $<0.05$ will be taken as significant.

\section{Results}

One hundred patents were taken up for laparoscopic cholecystectomy. Out of these 100 patients with gallbladder disease, 15 patients $(15 \%)$ were converted to OC . 95 patients were taken up for elective laparoscopic cholecystectomy and 5 were taken up as emergency procedure. All 5 patients taken up for emergency laparoscopic cholecystectomy were operated in first 48 hours of acute attack of cholecystitis. No patient presenting with an attack of acute cholecystitis was taken up for emergency surgery more than 48 hours later. In the elective setting 95 patients were taken up for elective laparoscopic cholecystectomy. 14 patients were taken up after conservative trial of 6 weeks, for acute cholecystitis 5 patients needed conversion.. 5 cases were asymptomatic and no conversion was needed. 76 patients had chronic cholecystitis and 8 patients required conversion. There were 34 male, and 66 female patients. Out of 34 male patients 10 needed conversion to OC. Only 5 of 66 female patients were converted to open procedure. There were 24 males < 60 years of age of which 6 required conversion to open procedure ( $25 \%$ ), as compared to 10 males $>60$ years of age of which 4 required conversion to open procedure $(40 \%),(\mathrm{p}=0.004)$ [Table1], which was significant. Out of 52 females $<60$ years of age 3 required conversion to open procedure ( $5.7 \%$ ) and of 14 females $>60$ years only 2 were converted to open procedure ( $14.2 \%$ ). This signifies elderly males $>60$ years were at significant risk for conversion to open procedure. Clinically patients presented with history of fever and pain in right hypochondrium. A ultrasound study was preformedin all the patients 5 patients presented with symptoms of acute cholecystitis which was confirmed radiologically on USG and computed tomography were taken for emergency LC within 48 hrs of their presentation. All 5 ( $33.3 \%$ ) patients were converted to open procedure because of inflammed, odematous gallbladder with dense adhesions ( $\mathrm{p}=0.00004)$ [Table 2]. Conversion to OC was significant in patients electively taken up for LC following an attack of acute cholecystitis. 5 ( $33.3 \%$ ) out of 14 patients required conversion to $\mathrm{OC}(\mathrm{p}=0.034)$. On ultrasonography finding of acute cholecystitis was highly significant, present in $5(33.3 \%)$ patients of which all 5 were converted $(\mathrm{p}<0.00004) .86$ patients had chronic cholecystitis but only 8 $(53.3 \%)$ patients were converted $(\mathrm{p}=0.108) .4$ patients had empymagall bladder but only $2(13.3 \%)$ patients were converted $(\mathrm{p}=0.693)$. Thickened gallbladder wall was present in 33 patients of which 10 required conversion ( $\mathrm{p}<0.001)$ [Table 3]. On ultrasonography presence of single or multiple stones $(\mathrm{p}=0.058)$ wae not significant.Conversion to OC was needed in two patients with cholecystoduodenal fistula discovered at 
operation and all were converted to open surgery. The defect in duodenum was repaired by absorbable sutures ( $\mathrm{p}=0.020$ ). Adhesions and fibrosis of Calot's triangle was encountered in 12 patients $(80 \%)$, and all were converted to open surgery $(\mathrm{p}<0.001)$ [Table 4]. Injury of the bile ducts occurred in only 1 patients $(0.12 \%)$, and the injury was identified . Intraoperatively $(\mathrm{p}=0.150)$. in this case the anatomy was obscured by adhesions caused by severe tissue inflammation.Four out of 7 patients having 1 or more episodes of gall stone pancreatitis were converted to OC . All 4 patients were males; 2 of them were $>60$ years of age.Post ERCP laparoscopic cholecystectomy showed higher significant conversion rate to open procedure compared with patients who had no prior ERCP intervention. 5 out of 6 patients who underwent LC following ERCP required conversion to OC $(\mathrm{p}<0.001)$ [Table 5].Previous surgery in the upper abdomen had occurred in 11 patients of which only $1(6.7 \%)$ require conversion to open surgery $(\mathrm{p}=1)$. Co-morbid illness like diabetes and hypertension had no significant contribution leading to open surgery in the study group. There were 22 patients in the study group who had diabetes of which 6 ( $40 \%$ ) required conversion to open surgery ( $p=0.068) .6(40 \%)$ patients out of 35 who had hypertension required conversion to open surgery $(\mathrm{p}=0.660)$. Demographic data and reasons for conversion are listed in [ Table 6].

\section{TABLES}

Table 1- Impact of gender on conversion

\begin{tabular}{|l|l|l|l|l|}
\hline Sex & Total Cases & Converted Cases & \% In Converted Group & p-value \\
\hline Male & 34 & 10 & 66.7 & $\mathbf{0 . 0 0 4}$ \\
\hline Female & 66 & 5 & 33.3 & 0.009 \\
\hline Total & 100 & 15 & & \\
\hline
\end{tabular}

Table 2: Patients presenting with acute and chronic cholecystitis

\begin{tabular}{|l|l|l|l|l|}
\hline & Laparoscopic Cases & Converted Cases & \%age & p-value \\
\hline Emergency & & & & \\
\hline$<48 \mathrm{Hrs}$ & 5 & 5 & 100 & 0.00004 \\
\hline$>48 \mathrm{Hrs}$ & 0 & 0 & 0 & 0 \\
\hline Elective & & & & \\
\hline Conservative treatments for 6weeks & 14 & 5 & 35.71 & 0.034 \\
\hline Asymmptomatic gall stones & 5 & 0 & $0 \%$ & - \\
\hline Chronic cholecystitis & 76 & 8 & 10.52 & 0.108 \\
\hline
\end{tabular}

Table 3-Factors on USG

\begin{tabular}{|l|l|l|l|l|}
\hline & Total no. Patients & Converted cases & \%age & p-value \\
\hline Acute cholecystitis & 5 & 5 & 33.3 & 0.00004 \\
\hline Chronic cholecystitis & 86 & 8 & 9.3 & 0.108 \\
\hline Thick walled & 33 & 10 & 66.7 & $<0.001$ \\
\hline Pus / empyema & 4 & 2 & 13.3 & 0.105 \\
\hline Single stone & 11 & 4 & 26.7 & 0.058 \\
\hline Multiple stone & 89 & 11 & 73.3 & 0.098 \\
\hline
\end{tabular}

Table 4- Intra operative factors - need for conversion

\begin{tabular}{|l|l|l|l|l|}
\hline & Total no. Patients & Converted cases & \% age & p-value \\
\hline $\begin{array}{l}\text { Gall bladder densely adherent with Omentum/ Colon/ } \\
\text { Duodenum/ Cholecystoduodenal fistula }\end{array}$ & 2 & 2 & 13.3 & 0.02 \\
\hline Gall bladder cannot be grasped/thick edematous & 33 & 10 & 60.7 & $<0.001$ \\
\hline Gall bladder needed to be aspirated Pus (Empyema) & 4 & 2 & 13.3 & 0.105 \\
\hline Calot's and anatomy undefinable & 12 & 12 & 80 & $<0.001$ \\
\hline Right sectoral duct injury & 1 & 1 & 6.150 \\
\hline
\end{tabular}

Table 5 Multivariate Analysis for Other Factors

\begin{tabular}{|l|l|l|l|l|}
\hline & Total no. Patients & Converted cases & \%age & p-value \\
\hline $\begin{array}{l}\text { H/o 1 or more attacks of } \\
\text { acute pancreatitis }\end{array}$ & 7 & 4 & 26.7 & 0.009 \\
\hline H/o jaundice & 2 & 1 & 6.7 & 0.279 \\
\hline Post ERCP & 6 & 5 & 33.3 & $<0.001$ \\
\hline Diabetes & 22 & 6 & 40 & 0.068 \\
\hline Hypertension & 35 & 6 & 40 & 0.660 \\
\hline $\begin{array}{l}\text { Previous upper abdominal } \\
\text { surgeries }\end{array}$ & 11 & 1 & 6.7 & 1.0 \\
\hline
\end{tabular}

Table 6-Reasons for conversion to open cholecystectomy

\begin{tabular}{|l|l|l|l|l|}
\hline Reason & Total Nos. of patients & Converted cases & $\%$ in converted gp & $\mathrm{p}$ value \\
\hline Sex & 34 & 10 & $66.7 \%$ & $\mathbf{0 . 0 0 4}$ \\
\hline \multicolumn{1}{|l|}{ Male } & & & & \\
\hline
\end{tabular}


Assesment of Risk Factors For Conversion To Open Surgery In Patients Undergoing

\begin{tabular}{|l|l|l|l|l|}
\hline \multicolumn{1}{|c|}{ Female } & 66 & 5 & $33.3 \%$ & 0.113 \\
\hline Age & 24 & 6 & $40 \%$ & 0.116 \\
\hline$>60$ yrs & & & & \\
\hline$\leq 60$ yrs & 76 & 9 & $60 \%$ & 0.068 \\
\hline Diabetes & 22 & 6 & $40 \%$ & 0.660 \\
\hline Hypertension & 35 & 6 & $40 \%$ & 1.0 \\
\hline Upper AbdSurg & 11 & 1 & $6.7 \%$ & $\mathbf{0 . 0 3 4}$ \\
\hline H/o Ac. Cholicystitis & 14 & 5 & $33.3 \%$ & 0.009 \\
\hline H/o Ac. Pancreatitis & 7 & 4 & $26.7 \%$ & 0.279 \\
\hline H/o Jaundice & 2 & 1 & $6.7 \%$ & $<0.001$ \\
\hline ERCP & 6 & 5 & $33.3 \%$ & \\
\hline
\end{tabular}

\section{Discussion}

Laparoscopic cholecystectomy is now the standard of care for symptomatic gallstone disease. Between $75 \%$ to $95 \%$ of all cholecystectomies are now performed laparoscopically. The well documented advantages are decreased postoperative pain, shorter hospital stay, early resumption of normal activity and improved cosmesisEfforts to further improve outcome of conventional LC has resulted in advent of single port laparoscopic cholecystectomy to minilaparoscopic techniques. However, the superiority of these new advanced technique is still being evaluated. For safe completion of cholecystectomy, conversion of LC to OC is required in certain situations. The risk for conversion has been estimated on the basis of clinical, labarotory and radiographic parameters. Recognition of these factors is important for understanding the characteristics of patients at a higher risk of conversion. Preoperative predictions of a difficult LC helps the surgeon to prepare better for the intraoperative risk and the technical difficulties expected to be encountered. Many workers believe that the need for conversion can only be establishaed with certainity during surgery, and the value of these variables is relative rather than absolute6,7In the literature widely varying conversion rates have been reported ranging from $2 \%$ to $15 \%$. In the present study, the conversion to open procedure was required in 15 patients ( $15 \%$ ). The most common reason for conversion to OC are difficult dissection and the inability to define the anatomy $8,9,10$ The influence of age on conversion rate remains controversial. Patients older than 70 years have a two-fold increase in conversion rate 11 . Various series have reported conversion rates of $4 \%$ to $16 \%$ in elderly patients scheduled for LC. Pavlidis et al ( 2008 ) in their study of LC in the extremely elderly ( $\geq 80$ years group ), had a conversion rate of $19 \%$. Another study has reported a $7.8 \%$ conversion rate in patients aged 80 years and older with complicated gallstone disease and this was not statistically different from the uncomplicated disease group12. Previous abdominal surgery is generally regarded as one of the factors of conversion for LC to OC, particularly after upper abdominal operations. In one study adhesions were found in $62 \%$ of patients after previous abdominal surgery, and this study documented that patients undergoing LC after previous abdominal surgery had a higher conversion rate ( $19 \%$ vs $52 \%$ ) compared with patients who had no prior surgery ( $5.4 \%$ vs $1.2 \%$ ), or compared with previous lower abdominal surgery ( $3.3 \%$ vs $0.7 \%) 13$. In the present study 11 patients had previous upper abdominal surgery and conversion to OC was required in only one patient ( $9 \%$ ). Our results corroborate other reports that document that previous abdominal surgery has little impact on the feasibility and safety of LC14,15. The thickened gallbladder wall is regarded as a risk factor for conversion. It is possible that recurrent episodes of acute cholecystitis in association with gallstones inevitably result in thickening and fibrosis of the gallbladder making grasping and dissection of the gallbladder very difficult14,16. Other reports also confirm a higher conversion rate in patients with a thickened gallbladder wall on ultrasonography17.Complicated gallstone disease - severe acute cholecystitis, empyema, gangrenous cholecystitis, Mirizzi syndrome, gallstone associated pancreatitis, and cirrhotic portal hypertension are all risk factors for higher conversion rate. Because of the small number of patients with complicated gallstone disease in the present study, their relevance to conversion rate cannot be commented upon. Two patients had cholecystoduodenal fistula and both were converted to an open procedure.

In both these patients, cholecystectomy and closure of the duodenal opening was performed. Conversion is needed for empyema and gangrenous cholecystitis. It is advocated that once such pathologies are identified, excessive time should not be spent in laparoscopic trial dissection before converting to an open operation72. In this study four patients had empyema and two patients were converted to open procedure.LC for acute cholecystitis incurs an overall increased incidence of conversion compared with elective LC. The risk in reported studies varies from $8 \%$ to $25 \% 18$. All five patients with acute cholecystitis in the present study needed conversion to OC. Lower conversion rate is reported if duration of symptoms is less than 96 hours5,14,19.The recognition of bile duct injury during LC is an indication for conversion. Majority of bile duct injuriesare diagnosed during surgery and necessitate conversion 14,20 . Out of $100 \mathrm{LC}$ in the present study, there was one patient with rightsectoral duct injury which was identified at surgery and appropriately managed and gallbladder bed drained. This patient had an uneventful recovery.

We attempted to study the conversion rate and identify the risk conversion factors necessitating conversion of laparoscopic cholecystectomy to open procedure. The data of patients who were attempted 
laparoscopic cholecystectomy wasanalysed in relation to conversion rate and reasons influencing conversion to open procedure. The study included 100 patients, 66 women, 34 men, with mean age of 51.87 years ( range 9 to 80 years ).Laparoscopic cholecystectomy was successfully performed in 85 patients. Conversion to open procedure was needed in 15 patients with conversion rate of $15 \%$ of all attempted laparoscopic cholecystectomies. Various conversion reasons identified were male sex, h/o acute cholecystitis, h/o of ERCP, USG findings suggestive of acute cholecystitis, dense adhesions, unclear anatomy due to dense adhesions in diagnosis of Calot's triangle were found to be associated with higher conversion. The conversion rate in this study was high. The most common reason was dense adhesions in Calot's triangle, and thickened, contracted gallbladder.Male gender with symptomatic cholelithiasis was associated with higher conversion.Patients undergoing emergency laparoscopic cholecystectomy had higher conversion rate. Significant conversion rate was seen in pre-operative USG confirmed cases of acute cholecystitis and post ERCP patients undergoing laparoscopic cholecystectomy.

\section{Conclusion}

In conclusion significant risk factors for conversion were male gender, acute cholecystitis, dense adhesions, post ERCP and pre-operative USG findings. Advanced age, previous upper abdominal surgery, jaundice, h/o pancreatitis, number of stones, biochemical profile were not found to be risk factors in our study. None of these risk factors were absolute contraindications to laparoscopic cholecystectomy but this may help predict the difficulty of the procedure and permit the surgeon to better inform patients about the risk of conversion. Knowledge of these factors may help in arranging operative schedule, psychological preparation, and planning of duration of convalescence.

\section{References}

[1]. Genc V, Sulaimanov M, Cipe G, Basceken SI, Erverdi N, Gural M, Aras N, Hazineddaroglu SM. What necessitates the conversion to open cholecystectomy? A retrospective analysis of 5164 consecutive laparoscopic operations. Clinics 2011; 66:417-420.

[2]. Harboe KM, Bardram L. The quality of cholecystectomy in Denmark: outcome and risk factors for 20307 patients from national database. SurgEndose 2011;25:1630-1641.

[3]. Sakpal SU, Bindra SS, Chamberlain RS. Laparoscopic cholecystectomy conversion rates two decades later. JSLS 2010 ; 14 : 476-483.

[4]. Kaafarani HMA, Smith TS, Neumayer L, Berger DM, Delalma RG, Itani KMF. Trends, outcomes, and predictors of open and conversion to open cholecystectomy in Veteavs Health Administration hospital. Am J Surg 2010; 200:32-40.

[5]. Kanaan SA, Murayama KM, Merriam LT, et al. Risk factors for conversion of laparoscopic to open cholecystectomy. J SurgRes 2002; 106: 20-24.

[6]. Brodsky A, Matter I, Sabo E, et al. Laparoscopic cholecystectomy for acute cholecystitis: can the need for conversion and the probability of complications be predicted? A prospective study SurgEndosc 2000;14:755-760.

[7]. Tamibyraja AL, Kumar S, Nixon SJ. Outcome of laparoscopic cholecystectomy in patients 80 years and older. World JSurg 2004; 28: 745-748.

[8]. Kanakala V, Borowski DW, Pellen MG, et al. Risk factors in laparoscopic cholecystectomy : a multivariate analysis. Int JSurg 2011, $9: 318-323$.

[9]. Sanjay P, Kulli C, Polignano F, etal. Optimal surgical technique, use of intraoperative cholangiography and management of acute gall bladder disease:the results of a nationwide survey in UK and Ireland. Ann RCollSurgEngl 2010; 92:302-306.

[10]. Llie AC, Nica C, Szucsik IA, et al. Preoperative ultrasonography as a mean of predicting the conversion of minicholecystectomy into classic cholecystectomy. Rev MedChirSoc Med Nat Lasi. 2009; 113:136-40.

[11]. Lill S, Rantala A, Vahlberg T, Gronroos JM. Elective laparoscopic cholecystectomy : the effect of age on conversion, complications and long term results. Dig Surg 2011; 28:205-209.

[12]. Leandros E, Alexakin N, Archontovcsilis F, et al. Outcome analysis of laparoscopic cholecystectomy in patients aged 80 years and older with complicated gallstone disease. J Laparoendosc andAdvSurg Tech 2007; 17:731-735.

[13]. Karayiannakis AJ, Polychronidis A, Pereute S, et al. Laparoscopic cholecystectomy in patients with previous upper or lower abdominal surgery. SurgEndosc 2004;18:97-101.

[14]. Alponat A, Kum CK, Koh BC, et al. Predictive factors for conversion of laparoscopic cholecystectomy. World JSurg 1997;21: 629-633.

[15]. Deiz J, Delbene R, Ferreres A. The feasibility of laparoscopic cholecystectomy in patients with previous abdominal surgery.HPBSurg 1998;10:353-356.

[16]. Kama N, Kologlu M, Doganay M, et al. A risk factor for conversion from laparoscopic to open cholecystectomy. Am J Surg 2001; 181: 520-525.

[17]. Rosen M, Brody F, Ponsky J. Predictive factors for conversion of laparoscopic cholecystectomy. Am JSurg 2002; 184: 254-8.

[18]. Livingstone EH, Rege RV. A nationwide study of conversion from laparoscopic to open cholecystectomy. Am JSurg 2004;188: 205-211.

[19]. Scollay JM, Mullen R, McPhillips G, Thompson AM. Mortality associated with treatment of gallstone disease: a 10 year contemporary national experience. World JSurg 2011;35:643-647.

[20]. Savassi- Rocha PR, Almeida SR, Sanches MD, et al. Iatrogenic bile duct injuries:amulticentric study of 91232 laparoscopic cholecystectomies performed in Brazil. SurgEndosc 2003;17:1356-1361. 